\title{
POLECAT: Preparatory and Modelling Studies
}

\author{
T. Peter'1, R. Müller'1, S. Pawson ${ }^{2}$ and H. Volkert ${ }^{3}$ \\ ${ }^{1}$ Max-Planck-Institut für Chemie, Postfach 3060, D-55020 Mainz, Germany \\ 2 Institut für Meteorologie, Freie Universität Berlin, Berlin, Germany \\ ${ }^{3}$ Institut für Physik der Atmosphäre, DLR, Oberpfaffenhofen, Germany
}

\begin{abstract}
"POLECAT" is the acronym for a mission to polar stratospheric clouds, lee waves, chemistry, aerosols and transport. It constitutes a lead project of the German ozone research program sponsored by the Federal Ministry of Education and Research (BMBF). It focusses on the investigation of polar stratospheric clouds (PSCs) in the northern hemisphere with special emphasis on mesoscale effects, in particular lee waves, and their effects on polar stratospheric chemistry. The project comprises two phases. Phase 1 will support laboratory studies on PSC microphysics and heterogeneous chemistry, modelling studies on all scales, and selected field experiments concerning particle measurements as well as characterization of the direct chemical products of heterogeneous reactions. Phase 2 will cover a mission of the high-altitude aircraft Strato-2C, used for flights along streamlines across orographically perturbed regions for direct investigation of PSC effects. This paper presents some preparatory work for the upcoming project and, hence, concentrates on modelling studies including the planning strategies for the future aircraft missions.
\end{abstract}

\section{KEYWORDS}

Stratospheric ozone; polar stratospheric clouds; aerosol microphysics; mountain waves; highaltitude aircraft mission.

\section{OBJECTIVES OF POLECAT}

\section{The POLECAT Project}

One of the most important remaining problems concerning ozone depletion in the northern hemisphere is the role of heterogeneous reactions on the surface of polar stratospheric cloud (PSC) particles in processing the stratospheric air. This processing leads to perturbations to the chemical composition of the air parcels during their passage through the clouds, because chlorine is activated, i.e. released to the environment in a form capable of inducing catalytic reactions with the odd oxygen family, while the odd nitrogen compounds are removed. Removal of odd nitrogen increases the potential of ozone depletion since odd nitrogen readily leads to deactivation of chlorine.

Northern hemisphere PSCs usually form in topographically-induced gravity waves, i.e. mountain waves and especially lee waves. Above and in the lee of mountains the adiabatic ascent of air parcels in their passage through the region can lead to rapid cooling and condensation of gases onto aerosol surfaces. PSCs tend to form in the climatologically coldest parts of the lower stratosphere, which lie in the North Scandinavian region (Pawson et al., 1993). PSCs form in the height range 18-24 $\mathrm{km}$ and lie above the cruising altitude of most aircraft, so direct measurements of such 
PSC particles are scarce up to date. There are thus many uncertainties regarding the chemical composition of PSC particles, their state (solid, liquid, or mixed), their size distribution, and their lifetime. These factors are affected by cloud microphysical parameters (e.g. formation rates at different temperatures, adsorption rates, etc.) and also dynamical factors (e.g. the mesoscale structure of the lee waves, which determine the local ascent and descent rates). Full understanding of the processing of air in PSCs thus requires knowledge of the dynamical, physical and chemical processes at work.

Observations at the required levels would first be available with a stratospheric research aircraft like the Strato-2C platform, which will be capable of high-altitude flights in the polar region (Schumann et al., 1992). Such observations would form an integral component of an observation system, supplemented by ground-based (radiosonde, radar, lidar) measurements of the atmospheric structure at certain locations and satellite data, which give information about the large-scale structures. Interpretation of observations generally requires the application of a models to supplemant the spatially limited data and to determine unmeasurable parameters (Peter and Crutzen, 1994). Furthermore, modelling studies can guide the acquisition of data: accurate numerical simulations of the structure of lee waves can be used at relatively short notice to determine when a measurement phase of a campaign should begin and guide the mobile platforms (the participating aircraft) to the most suitable locations (i.e., where the PSCs form).

The POLECAT campaign will address problems concerning the dynamics of mountain wave formation and the cloud microphysics of PSC formation in these waves. It will ultimately combine modelling and observational studies of these processes in an attempt to increase our knowledge of the processing of stratospheric air in PSCs. Inevitably, as we proceed to this goal, there will be advances in our scientific understanding of dynamical and cloud microphysical processes.

\section{Modelling Objectives of Phase 1}

This first phase of the POLECAT project is a preliminary study of three years duration in which modelling studies will be undertaken. Assuming that the observational phase of POLECAT takes place in winter 1998-99, this phase of the project should commence in summer 1995 in order that the necessary experience with the mesoscale modelling and the application of the cloud microphysics models to these data is attained.

Phase 1 will thus serve to provide a strong scientific background which would enable a more precise definition of the aims, requirements and strategy of the observational campaign. It will benefit from results from the SESAME campaign (Second European Stratospheric Arctic and Mid-latitude Experiment) of the EC, whose activities should lead to further understanding of PSC processes which would help define the POLECAT observations more precisely. Further, the participating groups will contribute to SESAME, meaning that they have access to the data, which may serve as a test data-base for the POLECAT modelling studies.

The modelling objectives of phase 1 of POLECAT are:

- The application of a mesoscale model (Mesoscop) to study the formation of topographically-induced gravity waves in realistically approximated flows for the Arctic during the SESAME observation periods.

- Coupling the dynamical models with cloud microphysics and heterogeneous chemistry modules, with the intention of understanding the interactions between microphysics, chemistry and mesoscale dynamics, thereby isolating the processes in lee-wave PSCs which lead to chlorine activation and consequently to ozone destruction.

- Problems concerning the effective combination of modelling of the lee-wave/PSC processes with observations. In particular, the most effective observation system needs to be defined: which measurements are most effective in which location?

- Some studies of the large-scale effects of the mesoscale chemical processing of air using northern hemispheric data and numerical models to investigate parcel dispersion and chemical perturbations. 
The participation in this project of groups with very different background enables effective investigation of the comprehensive problem. Work concerning PSC effects on air composition is performed at MPI/Mainz. The contribution to the dynamics, from the FUB group, is an important prerequisite to the microphysics work. This latter contribution will also be invaluable at the mission-planning stage. The dynamical contribution will be performed with the mesoscale model, Mesoscop, developed at the DLR/Oberpfaffenhofen; accordingly, their role is essential for the project.

\section{Phase 2}

The second phase of the project is anticipated to be larger than the first, including the missionscientists as well as more scientific staff in the modelling area, who would work to combine the observational and modelling areas more fully. The reason for this separation into two phases is due to the lack of experience in the areas of mesoscale modelling in the stratosphere and the integration of modelling and observations.

Phase 2 is very likely to include an international component, particularly in the observational aspects including instrumentation for Strato-2C, other aircraft, and ground-based measurements.

\section{STATE OF THE ART}

Heterogeneous chemistry on the surface of polar stratospheric cloud (PSC) particles in the low stratosphere sets the scene for the destruction of ozone through a complex sequence of chemical reactions. In the northern hemisphere, much of the particle formation occurs in lee-wave clouds, which form, for example, downstream of the Scandinavian mountains. The American AASE and European EASOE campaigns revealed their important role in the processing of stratospheric air, but many questions remain open concerning the dynamical and microphysical aspects of PSC structure and their chemical effects on the chlorine chemistry and the ozone budget of the winter and springtime northern hemisphere.

Observations of atmospheric trace gas and aerosol distributions made within the EASOE campaign have provided a wealth of data related to the potential of ozone destruction in the northern hemisphere (Pyle et al., 1994). Interpretation of these data generally requires a knowledge of the meteorological conditions, since these determine the trajectories followed by air parcels, which in turn determines the amount of chemical processing of the air - depending essentially on how long the air has spent passing through regions of PSCs and the details of the PSC particle distributions. While reasonably accurate large-scale trajectories (Knudsen and Carver, 1994) can be determined from meteorological data (see for example Fig.1), the details of how the air passes through clouds requires knowledge of the mesoscale dynamical structure in the lee of the mountains. This structure is known to affect the particle growth of the PSCs, and hence the chemistry.

Full details of these processes are not available from current observations, since they do not have sufficient density to observe the structure and evolution of the clouds. Numerical modelling studies have been proven to be useful in this respect, since they can provide detailed knowledge of the dynamics of the flow over and around mountains and of the mechanisms of cloud formation and evolution. Some modelling of orographic clouds in the stratosphere were made during EASOE (Volkert and Intes, 1992), albeit with a two-dimensional version of a mesoscale model (modelling the flow in the vertical plane perpendicular to the mountain range). Studies using trajectories from this model on which to perform calculations of PSC formation and heterogeneous chemistry (Peter et al., 1994) reveal some of the restrictions of the two dimensional model, pointing to the requirement of accurate three-dimensional models of PSC formation. It is thus essential to apply mesoscale models of the atmospheric flow to the problem of lee-wave formation, in order to study the interactions between the dynamics, cloud-particle formation, and heterogeneous chemistry on these cloud particles on scales not previously examined.

The mechanism of PSC formation determines the composition and form of the particles, which in turn affects their influence on the chemistry of the lower stratosphere. The natural background 


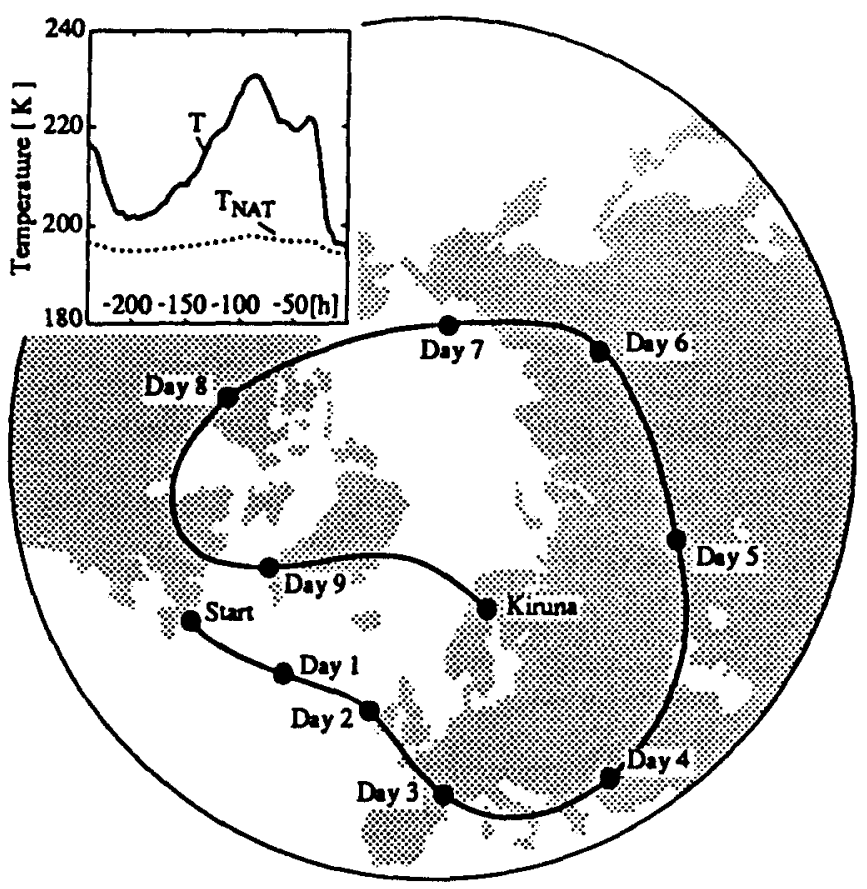

Fig.1. 10-day synoptic trajectory (from the Danish Meteorological Institute) based on analyses by ECMWF) at $475 \mathrm{~K}$ potential temperature ending at Kiruna on 27 January 1992. Insert: Temperature evolution for this trajectory (solid line) and $T_{\text {NAT }}$ (dotted line, nitric acid trihydrate equilibrium temperature). Such trajectories do not contain information on small-scale phenomena like lee waves, compare Fig.3.

aerosol, mainly sulfuric acid particles, acts as a condensation nucleus. In the Antarctic, the slow radiative cooling of the lower stratosphere, to temperatures lower than $190 \mathrm{~K}$ (see Fig.2), through the winter leads to the formation of 'mother of pearl' clouds, which consist of ice particles, whose sedimentation implies a dehydration of the lower stratosphere. This form of PSC occurs less often in the northern hemisphere due to the higher temperatures there. At higher temperatures (195 K) water vapour and nitric acid can simultaneously condense onto the aerosol in the lower stratosphere, possibly leading to the formation of nitric acid hydrates, most likely nitric acid trihydrate (NAT) (Crutzen and Arnold, 1986; Toon et al., 1986). Upon sedimentation this leads to a denitrification of the lower stratosphere. Further cooling can lead to ice condensation onto these NAT particles.

The temperatures in the Arctic lower stratosphere mean that NAT clouds are more likely to form than ice clouds. The adiabatic ascent in the lee waves also causes cooling, which is much more rapid than the diabatic cooling which dominates in the Antarctic, so the lee-wave PSCs form under different conditions than the synoptic-scale PSCs. It is well known that slow cooling leads to the formation of relatively few, large PSC particles while rapid cooling leads to more smaller particles (e.g. Toon et al., 1989; Larsen, 1991). Factors such as the length of time the particles remain cold and how cold they remain thus determine the characteristics of the PSCs and hence the chemical composition of the lower stratosphere. Some denitrification in the Arctic was observed by Schlager et al. (1990).

From a chemical point of view, the importance of PSCs is their ability to support heterogeneous surface reactions which lead to both rapid deactivation of active nitrogen (via $\mathrm{N}_{2} \mathrm{O}_{6}+\mathrm{H}_{2} \mathrm{O} \rightarrow$ $2 \mathrm{HNO}_{3}$ ) and rapid activation of chlorine from reservoir compounds (e.g. via $\mathrm{ClONO}_{2}+\mathrm{HCl} \rightarrow$ $\mathrm{Cl}_{2}$ and the subsequent photodissociation to $\mathrm{Cl}$ atoms). The chlorine activation directly primes 
ENVELOPE OF MINIMUM BRIGHTNESS TEMPERATURE 1980 - 1988 MSU CHANNEL 24 (ABOUT $90 \mathrm{mb}$ )

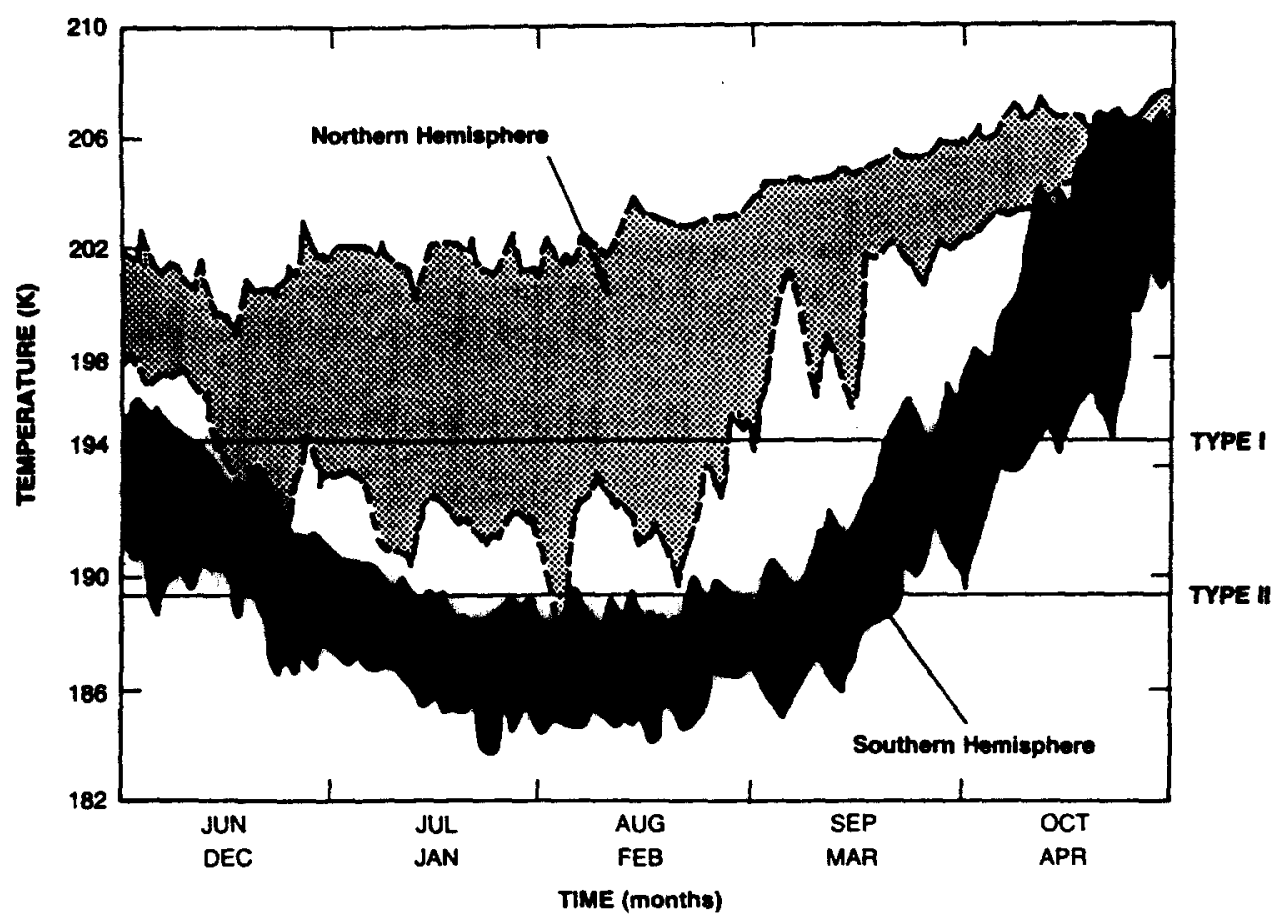

Fig.2. The range, near 90 mbar, of the minimum brightness temperatures poleward of $20^{\circ}$ latitude, computed daily for winter and spring from 1980 to 1988 . Heavy shading corresponds to the southern hemisphere from June to October (upper labels on the time axis). Light shading corresponds to the northern hemisphere from December to April (lower labels on the time axis). The horizontal lines across the figure represent the temperatures below which Type-I and Type-II PSCs can form. Note that these satellite data do not account for small-scale fluctuations like lee waves in orographically perturbed regions (from WMO, 1989).

the air for catalytic ozone destruction, while the nitrogen deactivation prevents the active chlorine from being immediately converted into inactive forms ( via $\mathrm{ClO}+\mathrm{NO}_{2}+\mathrm{M} \rightarrow \mathrm{ClONO}_{2}+\mathrm{M}$ ). The accompanying strong increase in the $\mathrm{ClO}$ mixing ratio has been convincingly revealed by recent MLS measurements (Waters et al., 1993). Furthermore, the sedimentation of particles may lead to partial denitrification, i.e. an irreversible loss of nitrogen species from the stratosphere to the troposphere with subsequently enhanced potential for ozone destruction.

It is thus clear that complete understanding of the ozone destruction arising from the heterogeneous chemical processes on cloud surfaces requires understanding of atmospheric dynamics and cloud microphysics as well as of heterogeneous and gas phase chemistry. The interpretation of data has been much improved by the use of trajectories derived from the meteorological observations, used in conjunction with box-models of the microphysics or chemistry. The microphysics models of Larsen (1991) and the chemical-microphysical model of Peter et al. $(1992,1994)$ and Müller et al. (1994) are examples of this type of approach. The results from these models suggest the need for more detailed understanding of the dynamical motions in the PSCs because of their influence on the other processes.

The small-scale chemical perturbations induced by PSC formation feed back into the large-scale distributions of ozone and other trace gases, as has been observed by satellite instruments. These 
measurements provide records of the evolution of the hemispheric ozone distribution and other trace gases associated with perturbed chemistry (e.g. Waters et al., 1993), albeit with restricted temporal and spatial resolution. Modelling studies of the stratospheric flow are generally essential to interpret the satellite data, isolating the relative roles of dynamics and chemistry in determining the evolution of the flow. For example, the existence of ozone mini-holes in the northern hemisphere has been attributed as being predominantly due to the dynamical effects of a raised tropopause during frontogenesis (Petzoldt et al., 1994), rather than photochemical ozone destruction. Some representations of the small-scale processes are required in the large-scale models; that is, it is necessary to refine parametrizations of heterogeneous ozone destruction (e.g. Cariolle et al., 1990) in the light of new information from EASOE and that to be obtained within SESAME.

\section{SCIENTIFIC DESCRIPTION OF THE MODELLING WORK}

The POLECAT mission is intended to address problems associated with ozone depletion due to the presence of PSCs in the northern winter stratosphere. The observational programme will include ground-based instruments at specific locations and in-situ and remote-sounding observations from aircraft. Notably, the Strato-2C high-flying aircraft will allow direct measurements to be made in the 18-24 km altitude range. Supporting data are likely to be available from satellites, standard meteorological observations, and numerical weather forecasts. The effective utilization of Strato$2 \mathrm{C}$ and the other instruments and carriers in the programme requires considerable planning to determine:

(a) the instruments to be carried;

(b) the most effective deployment of these instruments, which determines the timing and routing of aircraft;

(c) effective integration of the observations into numerical models to enable the precise investigation of causal mechanisms.

These problems require considerable pre-mission investigation, in order to reduce the number of uncertainties involved. The supportive modelling work will begin at an early stage to enable the necessary experience to be built so that the operational phase of the project can run smoothly. The special capabilities of Strato-2C introduce new aspects to the problem due to the unknown parameters encountered at its cruise altitude. Most especially, very little mesoscale modelling work has been undertaken in the stratosphere, so that the range of unknown parameters is large. Phase 1 of the POLECAT programme is aimed at gaining essential experience and obtaining knowledge of the processes which are likely to be encountered in the observational phase of the mission, thereby reducing the number of uncertainties in the parameters to be measured and providing guidelines to be adhered to during the measurements themselves.

The EASOE and AASE campaigns have illustrated the value of coordinated measurements of meteorological fields and trace gases and shown that analysis of such measurements can reveal much about inter-relations of the chemical composition, the dynamical state and the presence of PSCs in the Arctic lower stratosphere. The ongoing SESAME programme should provide further information about these processes. Even so, a large number of questions are likely to remain open, some of which can be addressed by the POLECAT project due to the new possibilities offered by the deployment of Strato-2C at high altitudes. The open problems are now introduced as a series of questions.

A fundamental process which is a prerequisite for the chemical destruction of ozone is the process ing of air on the surface of the cloud particles present in PSCs which form in the low stratosphere in the lee of the Scandinavian mountains. The significance of this location is that the wintertime polar vortex tends to be located asymmetrically, displaced from the pole towards Greenland, Scandinavia, or Siberia (Pawson et al., 1993; Naujokat et al., 1992). The coldest air thus tends to lie over these regions. The meteorological conditions generate gravity waves which can reach the lower stratosphere, where adiabatic cooling of air parcels leads to the possibility of PSC formation.

The amount of ozone destruction resulting from heterogeneous chemistry is dependent on the 
history of the air parcels involved. Typically, the air eirculates around the polar region within about five days. This means that over a period of several weeks the air potentially passes through PSCs several times, leading to repeated, accumulative disturbances of the chemical composition. This type of study, involving the use of microphyoical models and photochemical box models has been performed by several authors; the common requirement for such studies is the use of trajectories, either idealised (Drdla and Turco, 1991) or derived from meteorological data (e.g. Arnold et al., 1992; Peter et al., 1992; Müller et al., 1994; Petzoldt et al., 1994), compare Fig.1.

Current dynamical models are capable of simulating lee waves quite adequately, as shown by the two-dimensional model calculations of Volkert and Intes (1992), who simulated the crosemountain flow with a horizontal resolution of $3.6 \mathrm{~km}$ and a vertical resolution of $0.5 \mathrm{~km}$ (see Fig.3). Three-dimensional simulations are also possible with this non-hydrostatic model ("Mesoscop"; see Schumann et al., 1987). Other mesoscale models have also been used to simulate topographicallyinduced gravity waves; e.g. Shutts and Broad (1993), validated their model against radiosonde and aircraft measurements for a 3-D simulation over northern England, showing that the model performed quite well in many aspects of the simulation. Experience with Mesoscop has revealed that the simulations are sensitive to resolution, principally because finer scales of orography can be resolved when the horizontal resolution of the model is increased. Three immediate questions to be resolved are thus:

A. What horizontal resolution is required to adequately simulate the dynamics of lee-wave formation?

B. To what extent are two-dimensional simulations adequate?

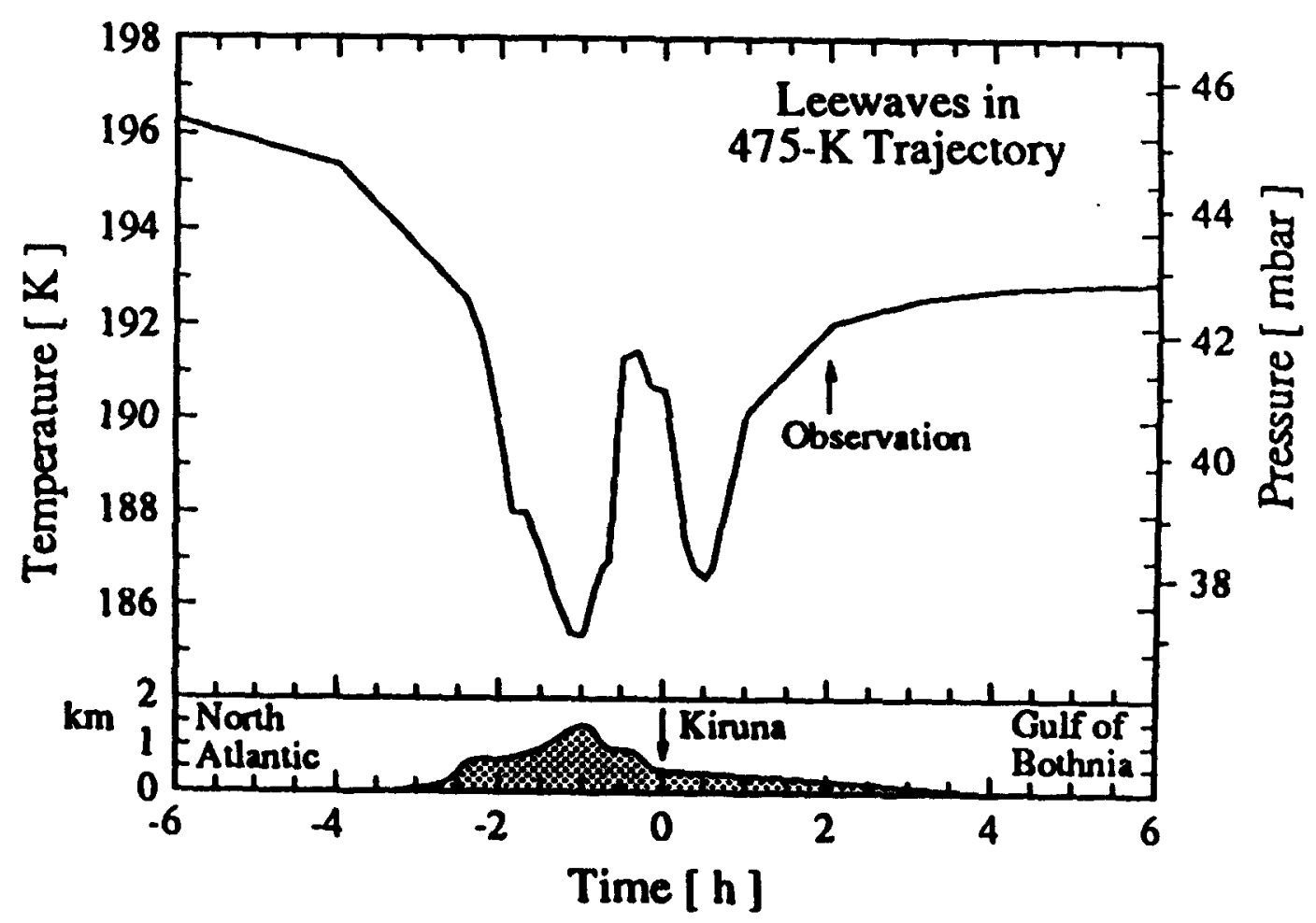

Fig.3. 12-hour trajectory at the $475-\mathrm{K}$ level $(\approx 19 \mathrm{~km})$ on January 27 , 1992 over Scandinavia. Time zero is at Kiruna (northern Sweden). The smoothed orography for the 2-D leo-wave model is shown below (from Peter et al., 1994; based on data by Volkert and Intes, 1992). 
C. What are the microphysical requirements with respect to the highly nonlinear temperature dependence of particle nucleation?

The third of these questions concerns the interactions between the dynamics and the particle formation and growth. As the mesoscale dynamics is resolved, the modelled trajectories become more detailed so that the temperature and pressure variations felt by the air include more smallscale structure, which is likely to influence the development of the cloud particles. The Mainz cloud microphysics model can be used on trajectories taken from dynamical models, and needs to be applied to integrations of varying resolution; the question is essentially whether the nonlinearities in particle nucleation and growth require the inclusion of details of the smallest scale or if a relatively coarse knowledge of the along-trajectory variations suffices. This question is of profound importance to the understanding of the particle size distribution, which may become decisive in relatively warm winters with only marginal chances for PSC formation (like the EASOE winter, 1991/92).

The detailed modelling of various microphysical processes (e.g. nucleation) depends strongly on assumed values of several essentially unknown parameters (e.g. the compatability factor in heterogeneous nucleation; Peter et al., 1992, 1994). Also the thermodynamics and the physical state of the $\mathrm{H}_{2} \mathrm{SO}_{4} / \mathrm{H}_{2} \mathrm{O}$ arosol particles (solid or liquid) is largely unknown (Luo et al., 1995; Koop et al., 1995). Only when these particles freeze can they serve as condensation nuclei for the sublimative formation of solid PSCs, as is assumed in most of the present large-scale models to date (conventional three-stage concept of PSC formation, see Fig.4). In the case that they remain liquid (Luo et al., 1994a), they grow into large particles due to uptake of $\mathrm{HNO}_{3}, \mathrm{H}_{2} \mathrm{O}$ and $\mathrm{HCl}$ (Luo et al., 1994b) into the liquid phase, as has been suggested by Carslaw et al. (1994) based on ER-2 measurements by Dye et al. (1992). Moreover, it is an unresolved problem whether the

\section{CONVENTIONAL 3-STAGE PSC-MODEL}

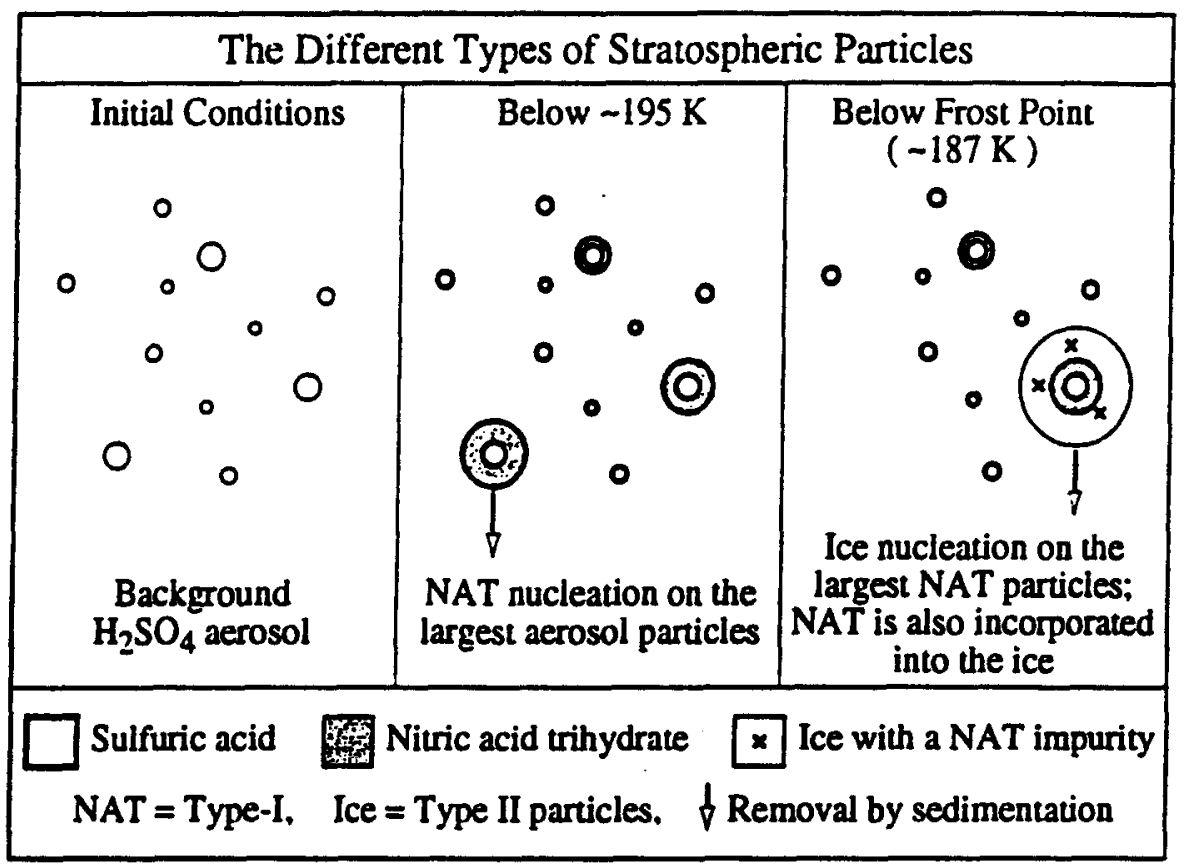

Fig.4. The conventional 3-stage model for particle formation. Left panel: background aerosol particles (typical radius $r<0.1 \mu \mathrm{m}$ ) assumed to be frozen. Centre panel: NAT formation $(r<1 \mu \mathrm{m})$ on the background aerosol. Right panel: Ice formation $(r<10 \mu \mathrm{m})$ on NAT particles. From Drdla and Turco (1990). 
particles, once they freeze out as water ice, can acquire a protective layer of nitric acid tribydrate ("NAT-Coating") which could considerably enhance the ice particle lifetime, see Fig.5 (Deshler et al., 1994; Peter et al., 1994; Peter and Baker, 1995). Hence, we arrive at the open question:

D. Can we place bounds on the ranges of the unknown parameters in the PSC nucleation and growth calculations?

and the important subquestion:

E. To what extent can mesoscale modelling in combination with the Strato-2C mission clarify the conditions under which ternary aerosol droplets freeze?

One possible method of tackling these tasks would be to compare modelled and observed particle characteristics. The Strato-2C would have to cruise along the streamlines, which the particles

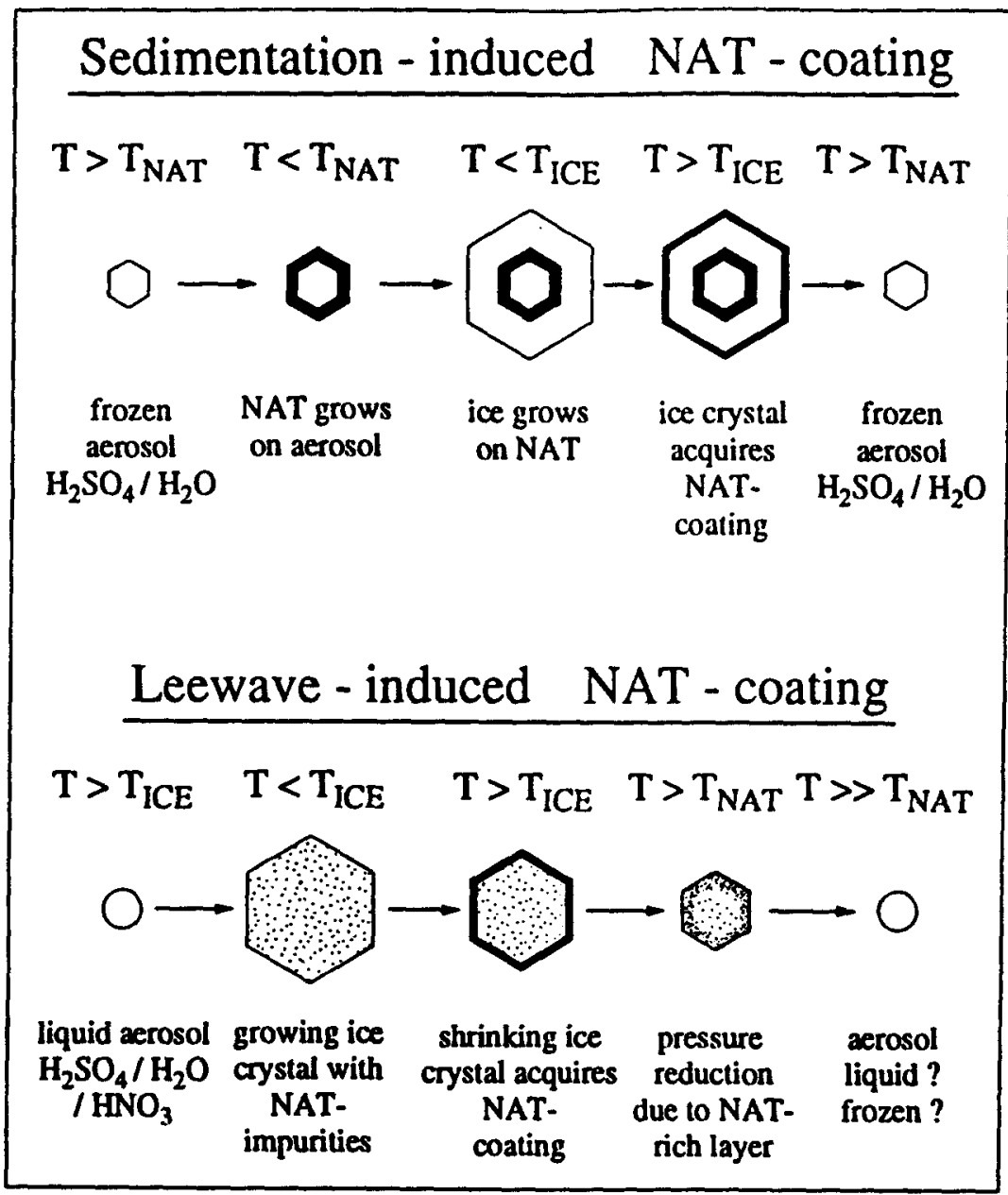

Fig.5. Fig.5: Upper panel: Sketch of the NAT coating mechanism proposed by Wofsy et al. (1990). Ice partilces sediment into warm regions where NAT particles have not yet formed and acquire a NAT coating which protects them against evaporation. Lower panel: Sketch of the evolution of an ice crystal with NAT-impurities nucleating in a liquid $\mathrm{H}_{2} \mathrm{SO}_{4} / \mathrm{H}_{2} \mathrm{O}$ aerosol particle. In this case ice evaporation is slowed due to a NAT-coating ( $T_{\text {ice }}<T<T_{\mathrm{NAT}}$ ) or due to a lowering of its vapour pressure $\left(T>T_{\mathrm{NAT}}\right)$. 
follow within the wave (i.e. cruise along quasi-Lagrangian trajectories), which up to now has not been ventured with the American ER-2 and which due to the characteristics of this aircraft cannot be readily undertaken in the future. Hence, only a few small-scale waves have been encountered by the ER-2 (Bacmeister et al., 1990). Of course, balloons can also fly along quasi-Lagrangian trajectories, but the meteorological conditions at the launching site (e.g. relatively low winds) do not allow a flexible deployment (e.g. from Andøya in front of the Scandinavian mountains). On the other hand, also the interpretation of the observations from high-altitude aircraft depends on the knowledge of the history of air parcels sampled by the aircraft, so that the answers to these questions depend somewhat on the answer to question $\mathrm{C}$. The central question question here is:

F. Can the Strato-2C be flown along air streamlines (i.e. quasi-Lagrangian trajectories) in order to study the life cycle of PSC particles from their formation to evaporation?

Another outstanding question concerning the modelling of dynamical-microphysical interactions is:

\section{G. Is the diabatic heating due to PSCs large enough to significantly affect the evolution of the dynamical fields?}

This is of fundamental importance, since it effectively determines whether the use of trajectories from previously-calculated model integrations is valid. The latent heat release due to cloud formation is probably small; large-scale perturbations to the radiative heating (e.g. Rosenfield et al., 1990) are also quite small but depend on the underlying surface. The small-scale effects on the radiation field have not been investigated. If this heating is large enough to influence the dynamics, moves must be made to incorporate the cloud particles as advected species in the models. This is not trivial: typical microphysical models would require several tens of advected parameters.

Atmospheric chemistry models which incorporate the effects of heterogeneous processes on the surface of the cloud particles are also available (Crutzen et al., 1992; Müller et al., 1994). Such models would be used within POLECAT to investigate the question:

\section{H. How sensitive is the chemical processing of air to the particle size distribution in PSCs?}

This question determines how possible uncertainties in the trajectories and the assumptions in the microphysics models affect the certainty of the calculated chemical perturbations caused by PSCs.

The composition and the physical state of PSC particles have a direct influence on the heterogeneous chemistry: surfaces of NAT, water ice and liquid particles have different reaction probabilities ( $\gamma$-values) and, hence, different potentials to process the air (z.B. Müller and Crutzen, 1993; Cox et al., 1994). Again it would be important to know whether ice particles have a coating (Peter et al., 1994). Furthermore, heterogeneous reactions in liquid aerosol will stop after freezing. The summary question is:

\section{To what degree is chemical processing of the polar winter stratosphere influenced by composition, physical state and morphology of the cloud and aerosol particles?}

Throughout the winter, satellite observations provide a history of the evolution of the largescale thermal and chemical composition of the northern hemisphere in middle and high latitudes. Natural changes are brought about by the annual cycle and dynamical changes, and these have been modelled successfully (e.g. Rose and Brasseur, 1989). Trace gas perturbations induced by heterogeneous chemistry have been reported by, e.g., Waters et al. (1993) and are indicative of large-scale effects of the presence of PSCs. Such effects need to be parametrized accurately for large-scale stratospheric circulation models (e.g. Cariolle et al., 1990) if the influence of the heterogeneous chemistry on the large-scale ozone depletion is to be understood; this suggests the question:

J. Can we improve current parametrizations of PSC-induced trace gas perturbations for use in large-scale stratospheric models? 
The use of stratospheric circulation models would enable us to make a study of the evolution of the trace gas distributions and offer a means of understanding the interactions between the resolved scales in satellite data (and the numerical models) and the small-scales. This is complementary to trajectory calculations, partly because of the global-scales involved, but also because more attention can be devoted to mixing processes between different latitude regions.

Solutions to such fundamental questions addressed above can lead to improvements in basic understanding, but importantly they allow correct interpretation of some outstanding problems in dynamics, microphysics and chemistry. In particular, these investigations could shed some light on the central question of the importance of the stratospheric aerosol for direct chlorine processing on/in the liquid $\mathrm{H}_{2} \mathrm{SO}_{4} / \mathrm{H}_{2} \mathrm{O}$ particles. This could be a key to answer the question (Stolarski et al., 1991):

\section{$K$. Does the observed mid-latitude ozone loss (TOMS) originate in the polar regions or is it produced in-situ by the ubiquitous aerosol?}

Solutions to many of the above questions can be provided by combining the use of numerical models with observed data. To this end, it is necessary to guide the observations with the use of forecasts of the stratospheric state. Very little effort has been devoted to optimizing observation systems in the stratosphere. Shutts et al. (1994) proposed a technique for observing tropospheric gravity waves, whereby several radiosondes with different ascent rates are employed to derive information about the horizontal and vertical wave structure. Lilly and Kennedy (1973) employed several aircraft at different altitudes to observe lee waves in the troposphere and lower stratosphere. The current problem is more complicated due to the uncertainty of radiosondes in reaching the stratosphere and the need to observe chemical constituents as well as meteorological fields. One can crudely anticipate that certain observations would be more useful than others but for such a mission to be successful more stringent criteria need to be imposed.

It is therefore essential that missions are pre-planned to that extent that certain 'optimal observation patterns' are defined. Thus, the mesoscale simulations of real situations would be used to define atmospheric states to be observed. These modelled states would then be artificially sampled using different combinations of instruments in various locations. This sampling of model data would include given instrumental characteristics from the apparatus to be deployed in the observational programme. The problem would then be to reconstruct and interpret as much of the model state as possible from the limited number of observations which would be available. In this manner, criteria for optimizing the observations should be determined.

Ideally, a variational mathematical solution would be obtained but the practical problems associated with such flights may render this unsuitable and redundant. The very minimum requirements are criteria to determine when to start flights, the relative flight paths when several aircraft fly simultaneously, and, for example, when drop-sondes can most effectively be deployed.

\section{RELATION TO OTHER RESEARCH ACTIVITIES OF BMBF}

The Ozonforschungs-Programm (OFP) of the German Ministery for Education and Research (BMBF) addresses problems of ozone depletion in the stratosphere, combining observational, laboratory and numerical modelling studies of chemistry, physics and dynamics. An important factor determining ozone depletion is the chemical processing of stratospheric air on PSC surfaces; as such the POLECAT project addresses key uncertainties which are directly related to the OFP and the results of POLECAT will have direct influence on the other OFP Lead Projects "Ozone variability" and "Prognostic Abilities".

The Strato-2C aircraft will enable in-situ observations of PSCs to be made, including the particle size distributions and chemical composition, as well as their state. In the POLECAT mission, Strato-2C would be deployed as an integral part of an observation system, involving ground-based measurements (radiosondes, ozonesondes, lidar and radar), other aircraft-based instruments, in combination with meteorological data from observations and numerical forecasts and satellite observations of the large-scale distributions of chemical trace gases. Strato-2C would be equiped 
with a variety of sensors for meteorological variables, chemical constituents, and aerosols. Effective deployment of such an aircraft requires fundamental understanding of the dynamical, physical and chemical processes involved in PSC formation and ozone destruction in order to guide the observations and reduce the number of unknown quantities in their interpretation. Therefore, phase 1 of the POLECAT mission comprises modelling and laboratory projects as well as the development of a few selected field experiments, designed to answer such fundamental problems and give a firm base for phase 2, which will include the observational phase of POLECAT, where the measurements must be integrated with the model results.

\section{REFERENCES}

Arnold, F., K. Petzoldt and E. Reimer (1992). Formation and sedimentation of stratospheric nitric acid aerosols: implications for polar ozone destruction, Geophys. Res. Lett., 19, 667-680.

Bacmeister, J., M.R. Schoeberl, L.R. Lait P.A. Newman and B. Gary (1990). Small-scale wave encountered during AASE, Geopys. Res. Lett., 17, 349-352.

Cariolle, D., A. Lasserre-Bigorry, J.-F. Royer, and J.-F. Geleyn (1990). A GCM simulation of the Springtime Antarctic ozone decrease and its impact on midlatitudes, J. Geophys. Res., 95, 1883-1898.

Carslaw, K.S., B.P. Luo, S.L. Clegg, Th. Peter, P. Brimblecombe und P.J. Crutzen, (1994). Stratospheric aerosol growth and $\mathrm{HNO}_{3}$ gas phase depletion from coupled $\mathrm{HNO}_{3}$ and water uptake by liquid particles, Geophys. Res. Lett., 21, 2479-2482.

Cox, R.A., A.R. MacKenzie, R.H. Müller, Th. Peter, and P.J. Crutzen (1994). Activation of stratospheric chlorine by reactions in liquid sulphuric acid, Geophys. Res. Lett., 21, 1439-1442.

Crutzen, P.J. and F. Arnold (1986). Nitric acid cloud formation in the cold antarctic stratosphere: a major cause for the springtime 'ozone hole', Nature, 324, 651-655.

Crutzen, P.J., R. Müller, C. Brühl, and Th. Peter (1992). On the potential importance of the gas phase reaction $\mathrm{CH}_{3} \mathrm{O}_{2}+\mathrm{ClO} \rightarrow \mathrm{ClOO}+\mathrm{CH}_{3} \mathrm{O}$ and the heterogeneous reaction $\mathrm{HOCl}+$ $\mathrm{HCl} \rightarrow \mathrm{H}_{2} \mathrm{O}+\mathrm{Cl}_{2}$ in "Ozone Hole" chemistry, Geophys. Res. Lett., 19, 1113-1116.

Deshler, T., Th. Peter, R. Müller and P.J. Crutzen (1994). The lifetime of leewave induced ice particles in the Arctic stratosphere: I. Observations, Geophys. Res. Lett., 21, 1327-1330.

Drdla, K. and R.P. Turco (1990). A one-dimensional model of Type-I and Type-II PSC formation with temperature oscillations, XV. General Assembly EGS, Copenhagen, April 1990.

Drdla, K. and R.P. Turco (1991). Denitrification through PSC formation: a 1-D model incorporating temperature oscillations, J. Atmos. Chem., 12, 318-366.

Dye, J.E., D. Baumgardner, B.W. Gandrud, S.W. Kawa, K.K. Kelly, M. Loewenstein, G.V. Ferry, K.R. Chan and B.L. Gary (1992). Particle size distributions in Arctic polar stratospheric clouds, growth and freezing of sulfuric acid droplets, and implications for cloud formation, J. Geophys. Res., 97, 8015-8034.

Koop, T., U.M. Biermann, W. Raber, B.P. Luo, P.J. Crutzen and Th. Peter (1995). Do stratospheric aerosol particles freeze above the ice frost point?, Geophys. Res. Lett., 22, 917-920.

Knudsen, B. and G.D. Carver (1994). Accuracy of the isentropic trajectories calulated for the EASOE campaign, Geophys. Res. Lett., 21, 1199-1202.

Larsen, N. (1991). Polar stratospheric clouds: a microphysical simulation model. DMI Scientific Report 91-2, DMI, Copenhagen, Denmark, 83pp.

Lilly, D.K. and P.J. Kennedy (1973). Observations of a stationary mountain wave and its associated momentum flux and energy dissipation, J. Atmos. Sci., 30, 1135-1152.

Luo, B.P., Th. Peter and P.J. Crutzen (1994a). On the freezing of sulfuric acid aerosol droplets in the stratosphere, Geophys. Res. Lett., 21, 1447-1450.

Luo, B.P., S.L. Clegg, Th. Peter, R. Müller and P.J. Crutzen (1994b). HCl solubility and liquid diffusion in $\mathrm{H}_{2} \mathrm{SO}_{4}$ acid under stratospheric conditions, Geophys. Res. Lett., 21, 49-52.

Luo, B.P., K.S. Carslaw, Th. Peter, S.L. Clegg (1994). Vapour pressures of $\mathrm{H}_{2} \mathrm{SO}_{4} / \mathrm{HNO}_{3} / \mathrm{HCl} /$ $\mathrm{HBr} / \mathrm{H}_{2} \mathrm{O}$ solutions to low stratospheric temperatures, Geophys. Res. Lett., 22, 247-250.

Müller, R. and P.J. Crutzen (1993). A possible role of galactic cosmic rays in chlorine activation during polar night, J. Geophys. Res., 98, 20483-20490.

Müller, R., Th. Peter, P.J. Crutzen, H. Oelhaf, G.P. Adrian, T. v. Clarmann, A. Wegner, U. 
Schmidt, and D. Lary (1994). Chlorine chemistry and the potential for orone depletion in the Arctic stratosphere in the winter of 1991/92, Geophys. Res. Lett., 21, 1427-1430.

Naujokat, B., K.Petzoldt, K. Labitzke, R. Lenschow, B. Rajewski, M. Wiesner, and R.C. Wohlfahrt (1992). The stratospheric winter 1991/92, the winter of the European Arctic Stratospheric Ozone Experiment, Beilage zur Berliner Wetterkarte, 24.6.

Pawson, S., K. Labitzke, R. Lenschow, B. Naujokat, B. Rajewski, M. Wiesner, and R.-C. Wohlfart (1993). Climatology of the northern hemisphere stratosphere derived from Berlin analyses. Part 1: Monthly means, Meteor. Abhandlungen, A7.3, Verlag von Dietrich Reimer, Berlin.

Peter, Th. and P.J. Crutzen (1994). Modelling the chemistry and micro-physics of the cold stratosphere. In: Low-temperature chemistry of the atmosphere, NATO ASI series, eds. G.K. Moortgat, A.J. Barnes, G. Le Bras, J.R. Sodeau, Springer, Berlin.

Peter, Th., R. Müller, K. Drdla, K. Petzoldt, and E. Reimer (1992). A micro-physical box model for EASOE: preliminary results for the January/February 1990 PSC event over Kiruna, Ber. d. Bunsengesellschaft $f$. Phys. Chemie, 96, 362-367.

Peter, Th., R. Müller, P.J. Crutzen, and T. Deshler (1994a). The Lifetime of Leewave-Induced Ice Particles in the Arctic Stratosphere: II. Stabilization Due to NAT-Coating, Geophys. Res. Lett., 21, 1331-1334.

Peter, Th. and M. Baker (1995). Lifetimes of ice crystals in the upper troposphere and stratosphere, in: Low-temperature chemistry of the atmosphere, NATO ASI series, eds. V. Ramanathan, P.J. Crutzen, Springer, Berlin, in press.

Petzoldt, K., B. Naujokat, and K. Neugebohren (1994). Correlation between stratospheric temperature, total ozone and tropospheric weather systems, Geophys. Res. Lett., 21, 1203-1206.

Pyle, J. et al. (1994). An overview of the EASOE campaign, Geophys. Res. Lett., 21, 1191-1194.

Rose, K. and G. Brasseur (1989). A 3-D model of chemically active trace species in the middle atmosphere during disturbed winter conditions, J. Geophys. Res., 94, 16387-16403.

Rosenfield, J.E., M.R. Schoeberl, L.R. Lait, P.A. Newman., M.H. Proffitt, and K.K. Kelly (1990). Radiative heating rates during the airborne AASE, Geophys. Res. Lett., 17, 345-348.

Schlager, H., F. Arnold, D.J. Hofmann and T. Deshler (1990). Balloon observations of nitric acid aerosol formation in the Arctic stratosphere, Geophys. Res. Lett., 17, 1275-1278.

Schumann, U., T. Hauf, H. Höller, H. Schmidt, and H. Volkert (1987). A mesoscale model for the simulation of turbulence, clouds, and flow over mountains: formulation and validation examples, Beitr. Phys. Atmos., 60, 413-446.

Schumann, U., F. Arnold, H. Fischer, R. Furrer, S. Pawson, U. Platt, E. Raschke, R. Roth, U. Schmidt, and R. Zellner (1992). Wissenschaftlich-technisches Konzept für die Nutzung des Böhenforschungsflugzeugs STRATO-2C, DLR-Report, Oberpfaffenhofen.

Shutts, G. and A. Broad (1993). A case study of lee waves over the Lake District in northern England, Quart. J. R. Meteorol. Soc., 119, 377-408.

Shutts, G., P. Healey, and S.D. Mobbs (1994). A multiple sounding technique for the study of gravity waves, Quart. J. R. Meteorol. Soc., 120, 58-78.

Stolarski, R.S., P. Bloomfield, R.D. McPeters and J.R. Herman (1991). Total ozone trends deduced from Nimbus 7 TOMS data, Geophys. Res. Lett., 18, 1015-1018.

Toon, O.B., P. Hamill, R.P. Turco, and J. Pinto (1986). Condensation of $\mathrm{HNO}_{3}$ and $\mathrm{HCl}$ in the winter polar stratospheres, Geophys. Res. Lett., 13, 1284-1287.

Toon, O.B., R.P. Turco, J. Jordan, J. Goodman, and G. Ferry (1989). Physical Processes in polar stratospheric ice clouds, J. Geophys. Res., 94, 11359-11380.

Volkert, H. and D. Intes (1992). Orographically forced stratospheric waves over northern Scandinavia, Geophys. Res. Lett., 19, 1205-1208.

Waters, J.W., L.Froidevaux, W.G. Read, G.L. Manney, L.S. Elson, D.A. Flower, R.F. Jarnot and R.S. Harwood (1993). Stratospheric $\mathrm{ClO}$ and ozone from the microwave limb sounder on the upper atmosphere research satellite, Nature, 362, 597-602.

WMO (1989). Scientific assessment of stratospheric ozone: 1989, World Meteorological Organization, Global Ozone Research and Monitoring Project - Report No. 10, Geneva/Switzerland.

Wofsy, S.C., R.J. Salawitch, J.H. Yatteau, M.B. McElroy, B.W. Gandrud, J.E. Dye and D. Baumgardner (1990). Condensation of $\mathrm{HNO}_{3}$ on falling ice particles: mechanism for denitrification of the polar stratosphere, Geophys. Res. Lett., 17, 449-452. 